\title{
Valuation: From The Discounted Cash Flows (DCF) Approach To The Real Options Approach (ROA)
}

Author: Cecilia Maya Ochoa ${ }^{1}$

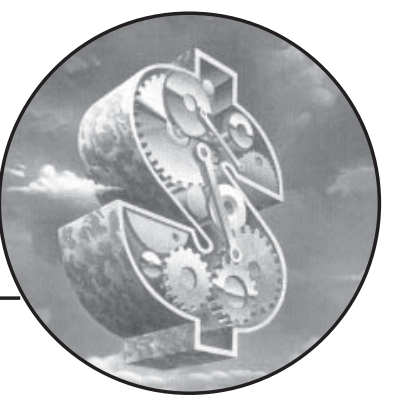

\begin{abstract}
There exists an abysm between market prices and traditional valuation approaches such as Discounted Cash Flows (DCF), a fact that neither academics nor practitioners could continue ignoring. Recently, a complementary approach has taken a foothold into the valuation world. Building on the DCF approach yet going further in the sense of incorporating flexibility in management investment decisions, and taking advantage of the advances in option pricing theory, the real options approach (ROA) has become the alternative to capital budgeting and, lately, to corporate valuation. Empirical evidence shows that ROA explains actual prices better than DCF approaches and nowadays there is no question that from a theoretical point of view, ROA is a much more appealing concept than passive NPV. However, its acceptance by practitioners has been very slow due to the complexity of real options pricing.
\end{abstract}

\section{Resumen}

Existe un abismo entre precios de Mercado y la valoración estimada por métodos tradicionales tales como Flujos de Caja Descontados, un hecho que ni académicos ni practicantes pueden continuar ignorando. Recientemente, una metodología complementaria ha tomado gran fuerza. Partiendo de los Flujos de Caja Descontados, pero incorporando flexibilidad en las decisiones de inversión y aprovechando los avances en la teoría de valoración de opciones, el enfoque de opciones reales ( $\mathrm{ROA}$ ) se ha convertido en la alternativa para presupuestación de capital y valoración de empresas. La evidencia empírica muestra que ROA explica los precios de mercado mejor que los enfoques basados en flujos de caja descontados y, hoy en día, no hay discusión de que es más atractivo desde un punto de vista teórico; sin embargo, su utilización en la práctica ha sido muy limitada debido a las dificultades que presenta la valoración de las opciones reales.

Key Words: Real Options, Valuation, Discounted Cash Flows, Net Present Value, Capital Budgeting. Palabras Clave: Opciones reales, Valoración, Flujos de Caja Descontados, Valor Presente Neto, Presupuesto de Capital.

${ }^{1}$ Ph.D. Internacional Economics and Finance. Department of Finance, School of Management, Universidad EAFIT.

E-mail: cmaya@eafit.edu.co 
CAPITAL BUDGETING AND

CORPORATE VALUATION METHODS: NEED FOR A CHANGE?

It took more than twenty years for Discounted Cash Flows Approaches (DCF), mainly the NPV approach, to replace Years to Payback and other ancient methods for capital budgeting and corporate valuation purposes. Yet this long wait proved to be worthy since after positioning itself as the most widely used approach to valuation, its reign seemed endless. Still in the nineties it continued to be the main approach, albeit an abysm between market prices and DCF values, a fact that neither academics nor practitioners could continue ignoring.

Although it is true that part of that difference was caused by a market bubble formed around Internet stocks which pushed up prices of growth stocks mainly, it is also true that once the bubble burst in 2000 , market valuations remained higher than their initial level. A study by Ernst and Young ${ }^{2}$ estimates that only $25 \%$ of market capitalization at the time of the study was based on cash flow anticipated in the next five years in a sample that included both growth and value stocks. Certainly, new approaches to valuation needed to be put in place.

During the Internet madness in the nineties, very peculiar approaches to valuation were suggested -and implemented!- in a wide range that included computing multiples of

${ }^{2}$ Campbell, J. and C. Knoess. "How to Build a FutureWealth Company, Ernst and Young's Point of View on Value on the New Economy". http://www.ey.com/GLOBAL. Cited in Boer (2002).
Market Price to Revenue up to multiples of the number of visitors to the Internet firm's web page. For a while, the market forgot about the essentials of firm's value such as its ability to generate future cash flows to shareholders -the basis for DCF- or to create value in general.

Simultaneously, a much more appealing approach -from a theoretical point of viewwas taking a foothold into the valuation world. Building on the DCF approach yet going further in the sense of incorporating flexibility in management investment decisions and taking advantage of the advances in option pricing theory, the real options approach (ROA) has become the alternative approach to capital budgeting and, lately, to corporate valuation. It is precisely the fact that ROA is based on a properly estimated NPV what explains the perception of practitionersthat, morethan a revolutionary solution, it is "an evolutionary process to improve the valuation of investments and the allocation of capital, thereby increasing shareholders value" (Triantis and Borison, 2001, p.10).

But before discussing how ROA builds on and complements the DCF approach, particularly the passive NPV, I present an overview of the different traditional methods which have been used for capital budgeting and corporate valuation. Examining these traditional methods will show the reasons why we need to evolve to a more comprehensive approach to valuation as, I will argue, it is ROA. 


\section{Traditional Approaches to value. An Overview}

\subsection{Years to Payback and Other Ancient Methods. Book Value, Liquidation Value, and Tobin's q.}

Before the long reign of the Net Present Value (NPV) approach, managers based their decisions about undertaking projects on simple rules such as the Payback rule. In order to apply it, the Payback period of a project is computed by counting the number of years it takes before the cumulative forecasted cash flow equals the initial investment. If this period does not exceed the cutoff date considered appropriate for the project, according to management, the project is accepted. This rule has been criticized because it ignores all cash flows after the cutoff date and it gives equal weight to all cash flows before this date. (Brealey and Myers, 2000). In other words, this rule ignores not only the time value of money -although some managers used the discounted-payback version of it - but also leads to rejection of projects with low cash flows in the beginning, even though future cash flows would fully compensate for the initial investment.

Compared to other methods, at least this Payback rule is based on cash flows. Some other commonly used methods for corporate valuation are based on the firm's balance sheet information, i.e. the book value, the liquidation value, and the replacement cost. Since this information obeys accounting rules, in most cases is not a good estimate of the firm's value as it is discussed next.

The book value is the net worth of a company as shown in the balance sheet. However, this value depends on the selection of a depreciation method for fixed assets and the fact that the price of these assets is the historical price, not the current one. In relation to the Book Value to Market Value ratio, it often indicates that accountants are missing something in their books since the market consistently is valuing companies a lot over their book values. It is true that assets are registered by their historical prices, but that argument can tell only part of the story. Today, there is no discussion that Book Value is an inadequate method to value firms and its usefulness is confined to provide a floor for the true value.

Another measure that sets a floor to the value of the firm is the liquidation value. It "represents the amount of money that could be realized by breaking up the firm, selling its assets, repaying its debt, and distributing the remainder to the shareholders" (Bodie, Kane, Marcus, 2002).

If the previous measures establish a floor to the firm's value, the replacement cost provides a cap for it because when the market value of a firm is above the replacement cost, it would be better for investors to replicate the firm. In consequence, the ratio of market price to replacement cost -known as the Tobin's $q$ - should tend to one. However, there is much evidence on the fact that this ratio is frequently above one, i.e. Linderberg and Ross (1981). These authors propose market share, concentration of the market, and barriers to entry as possible factors explaining why some firms exhibit a $q$ greater than one.

\subsection{EVA: Searching for the Economic Value}

A somewhat different measure of the value of a project or a firm is the Economic Value. In the nineties, Stern Stewart reintroduced the Economic Value Added (EVA) concept which is computed as the net operating profit after taxes (NOPAT) minus an appropriate charge for the opportunity cost of all capital invested in the enterprise. Economic Value is, then, the sum of the EVAs added by the enterprise in each successive year. EVA is an estimate of the 
amount by which earnings exceed or fall short of the required minimum rate of return which shareholders and lenders might earn by investing in alternative securities of comparable risk (Boer, 2002). Put in different words, it is the difference between the return on assets (ROA) and the cost of capital multiplied by the capital invested by the firm (Bodie, Kane, Marcus, 2002). EVA is an important and popular measure of firm's performance, but its application remains more at this level than as a valuation method.

\subsection{The Discounted Cash Flows Approach: passive NPV, IRR, and Risk-Weighted Cost of Capital}

This valuation approach applies to both project and corporate valuation. It is based on the free cash flows the project or entity will generate in the future which are defined as the net cash flows to shareholders after future investments. This approach improves over the previous methods in the sense that it measures the ability to generate cash and, as such, it gives a better estimate of the shareholder's wealth created by the project or entity. After computing the free cash flows, they are discounted at an appropriate rate equals to the opportunity cost of capital and the initial investment required by the project is deducted to obtain the Net Present Value (NPV) of the project:

$\mathrm{NPV}=\sum_{t=1}^{T} \frac{E\left(F C F_{t}\right)}{(1+k)^{t}}-I$

where:

$E(F C F t)$ is the expected free cash flow of the project at time $t$;

$k$ is the opportunity cost of capital;

$I$ is the required initial investment.

The "Net Present Value (NPV) is the single most widely used tool for large investments made by corporations" currently (Copeland, Antikarov, 2001, p.56).These authors cite evidence showing that the use of this approach in corporate America increased from 19\% to $86 \%$ of the firms surveyed in a period of less than twenty years - 1959 to 1978 -.

There are two equivalent ways to computing the passive NPV. The first one is discounting the free cash flows to equity at the cost of equity where these free cash flows are equal to:

FCF to equity $=$

Net Income + Depreciation - Capital Expenditures

A second way to calculate the passive NPV is discounting the free cash flows from operations at the weighted average cost of capital. These free cash flows are the after - tax cash flows the entity would have if it had no debt and may be computed in the following manner:

\begin{tabular}{l} 
Earnings Before Interest and Taxes \\
$($ EBIT $)$ \\
- Taxes on EBIT \\
+ Depreciation \\
- Capital Expenditures \\
\hline$=$ FCF from Operations
\end{tabular}

The corresponding discounting rates, that is, the cost of equity and the weighted average cost of capital will be explained shortly. Once the passive NPV is computed, the rule says that managers should undertake the project if it has a positive passive NPV.

A related approach, also based on discounted cash flows, is the internal rate of return (IRR) of the project, also known as the discounted cash flows (DCF) rate of return. This is the rate of discount which makes the passive NPV equals to zero. A project would be accepted if its IRR is greater than the opportunity cost of capital. Although this approach provides a rule to accept or reject investments, it does not answer the question of which is their value as it does the NPV approach. 
Additional to being a method based on cash flows, the NPV approach also improves over the previous methods by accounting for both the time value of money and the risk aversion, all combined through the risk-adjusted discount rate. The risk-adjusted discount rate, $k$, is the sum of the risk-free interest rate which accounts for the time value of money and a risk premium, $\Psi$, used to compensate for the risk associated with the project. (Trigeorgis, 1986).

The firm's average opportunity cost of capital may be used to discount the expected project's free cash flows if the riskyness of the project is similar to that of the firm; otherwise, the marginal opportunity cost of capital for the particular project should be used. Frequently a constant discount rate is used but the riskyness of the cash flows from the project may vary through time, suggesting that a risk-adjusted discount rate appropriate for each period should be used instead of a constant one.

The question remains of how to compute this risk-adjusted discount rate. If the passive NPV is computed discounting the free cash flows to equity, the cost of equity shall be estimated. For this purpose, the Capital Asset Pricing Model (CAPM) is the most common approach:

$$
\begin{aligned}
& r_{i}-r_{f}=\beta_{i}\left(r_{m}-r_{f}\right) \\
& \beta_{i}=\frac{\operatorname{Cov}\left(r_{i}, r_{m}\right)}{\sigma^{2}{ }_{m}}
\end{aligned}
$$

where:

$\mathrm{r}_{i}:$ the return on asset $i$;

$\mathrm{r}_{f}$ : the risk-free rate;

$\beta_{i}$ : the beta of asset $i$;

$\mathrm{r}_{m}$ : the return on the market portfolio;

$\sigma_{2 m}$ : the variance of the market porfolio's returns;

The CAPM considers an investor who may diversify the risk through a portfolio comprising all the securities in the market.
This investor requires a certain risk premium from each security according to its marginal contribution to the riskyness of the market portfolio. However, the total risk of each asset involves two different components: a systematic risk which affects all the securities in the market and it is non diversifiable since it depends on the correlation between the asset's return and the market portfolio's return as measured by its beta; the other component is the non systematic risk, which depends on characteristics or factors that affect each individual security, therefore, it can be diversified away. In consequence, the investor should demand a risk premium from the asset to compensate for its systematic risk only.

If its beta remains constant through the entire time of the project, a constant $k$ may be used to discount its cash flows. However, frequently that is not the case since as Myers and Turnbull (1977) $)^{3}$ point out, a project's beta depends on its life, the growth rate of its expected cash flows, the pattern of the expected cash flows over time, the characteristics of any individual underlying components of these cash flows, the procedure by which investors revise their expectations of cash flows, and the relationship between forecast errors for the cash flows and those for the market return. The security which beta is going to be used as the beta for the project should match the project in all these aspects. Otherwise, when the project's beta varies through time, a generalized riskadjusted discount rate form of NPV with a varying $k$ should be computed as opposed to the single risk-adjusted discount rate NPV from equation (1.1).

$\mathrm{NPV}=\sum_{\mathrm{t}=1}^{\mathrm{T}} \frac{\mathrm{E}\left(\mathrm{FCF}_{\mathrm{t}}\right)}{\left(1+\mathrm{k}_{1}\right) \ldots \ldots\left(1+\mathrm{k}_{\mathrm{t}}\right)}-\mathrm{I}$

The other way to compute the passive NPV is discounting the operating free cash

${ }^{3}$ Cited by Trigeorgis (1986) 
flows instead of the free cash flows to equity. In this case, the weighted average cost of capital (WACC) should be used as the risk-adjusted discount rate. The WACC is the weighted average of the after-tax marginal costs of capital which includes the costs of both sources of capital: equity and debt. The previous analysis in relation to using a constant or a varying riskadjusted discount rate applies here as well.

Finally, a last consideration shall be made when applying the NPV approach: "if NPV is calculated using an appropriate riskadjusted discount rate, any further adjustment for risk is double counting" Myers (1976) i.e. adjusting for risk both, the free cash flows and the discount rate, will be a mistake. This leads us to different approaches to valuation which handle uncertainty by focusing mainly on the risk associated with future cash flows instead of adjusting the discount rate for risk. These approaches are Sensitivity Analysis and Monte Carlo Simulation.

Free cash flows are usually the result of forecasting a number of variables such as unit product price, quantity of sales, growth, salvage value, etc. A sensitivity analysis tries to measure the change in the NPV as a result of a change in one of these variables, keeping the others constant. The main objective is to identify to which variables the NPV is more sensitive, hence, which ones are more determinant of the investment's risk. Once these variables are identified, management should be especially careful forecasting them.

Although sensitivity analysis provides more information for management to make decisions, it could eventually mislead it since it assumes that all variables are independent and not serially correlated. In the first case, when some variables are not independent, changing one variable while keeping constant the correlated variables will lead to a wrong estimation. The same happens when variables are serially correlated since a forecast error in one period will affect its value for future periods, generating a wrong estimate of the NPV at the end. One way to get a better estimation is by changing combinations of variables which may be correlated instead of changing just a single variable. However, there is a better methodology known as the Monte Carlo simulation method which considers all possible combinations of variables.

The Monte Carlo method estimates NPV by generating random samples of the main variables which determine the project's cash flows based on their probability distributions. Firstly, it models the project with a set of mathematical equations and identities describing the relationship among the different variables involved. Secondly, it specifies a probability distribution for each variable, empirically or subjectively, and the correlation among variables. Finally, it draws a random sample based on the defined distribution for each value and computes the NPV for each sample. All these sample NPV generate a probability distribution from which the expected NPV may be estimated as well as its standard deviation, along with other statistics.

The previous approach provides a probability distribution of NPV, not cash flows. If these NPVs are correctly computed, they should have been discounted at the risk-free rate. Discounting them at a risk-adjusted rate would be accounting twice for risk according to Myers (1976) quoted above. On the other hand, applying the Monte Carlo method gives as a result a probability distribution of the NPV, which is hard to associate with the price of an asset in a competitive market, the original question on valuation. Due to this critique, Brealey and Myers (2000, p.275) recommend to use simulation "not to generate a distribution of NPVs. Use it to understand the project, forecast its expected cash flows, and assess its risk. Then calculate NPV the old-fashioned way, by 
discounting expected cash flows at a discount rate appropriate for the project's risk".

Adding sensitivity analysis and simulating cash flows to compute NPV certainly improve the passive NPV approach to valuation. However, all these NPV approaches present a serious flaw since it assumes, from the beginning of the project, a commitment to certain investments which will be made at fixed points in time. In the real world, management may wait until more information is gathered i.e. about the product or the market, before committing more money to the project. As time passes and more information is available, uncertainty decreases and the management may make a better decision. This is the main critique to the NPV approach which has lead to the search of a better valuation method that incorporates the flexibility management has to change the initial plans at a future time. Two approaches have been developed for this purpose: Decision Tree Analysis (DTA) and Real Options Approach (ROA).

\subsection{Decision Tree Analysis (DTA)}

The DTA recognizes the interdependencies between the initial and the subsequent investment decisions. It allows to map out all the different alternatives that management will have at different points in time conditional on the state of nature. In that way, it allows analyzing complex sequential investment decisions when uncertainty is resolved at discrete points in time, not only at the initial one as it is the case in the NPV approach.

In order to apply DTA, a tree is build where each branch represents a state of nature at a certain point in time. At each node, management should choose the alternative which maximizes the risk-adjusted expected NPV. In this way, this approach allows to incorporate flexibility recognizing that future decisions will depend on which is the state of nature at that point in time, that is, the decision needs not to be made today when management is deciding whether to undertake the project or not. This initial decision is the only one to which the management is committed to. All this makes DTA appealing as a valuation method but applying it in the real world is very hard.

In practice, when a complex reality is being portrait, the tree becomes really cumbersome. This tree branches at each period, for each state of nature, and for each decision that may be taken. For all these reasons, the tree grows exponentially. Restricting DTA to the minimum number of cases may help but, by doing so, managers may incur in an oversimplification which can lead to an inadequate decision.

Yet this is not the main critique to DTA. The most important flaw of this approach is the use of a constant discount rate along the entire tree. By doing this, it assumes that uncertainty is resolved continuously at a constant rate over time, when the tree has been built considering discrete events, therefore, different discount rates should be used for each period. As Trigeorgis (1986) points out, some authors try to solve this problem by discounting cash flows at the risk-free rate and then deciding on the basis of the distribution of NPV. This solution is inconsistent with building a tree forward using the actual probabilities and the expected rate of return and then moving backwards discounting at the risk-free rate.

The main conclusion after the previous analysis of sensitivity analysis, simulation, and DTA, is that "although these methodologies have been helpful in improving management's understanding of the structure of the investment decision, nevertheless stop short of offering a manageable, consistent solution" (Trigeorgis, 1986, p.63). On the other hand, even though DTA goes one step forward by incorporating flexibility, it is hard to apply it in the real world. 
Next, I will present a more recent valuation methodology, known as the real options approach (ROA), which overcomes all the critiques made to the previous methods.

\section{From The NPV approach to ROA}

The reign of the DCF, particularly the NPV approach, has lasted for decades up to our time. However, as Boer (2002) remarks, "the era of discounted cash flows came to an end,..., in part because of a growing crisis in valuation. In effect, while the concept of basing value on cash flows was by itself intellectually impregnable, the marketplace was rejecting it. Sky-high valuations were accorded to companies with promising intellectual property but minuscule or negative short-term cash flow. At the same time, investments in "value" stocks, those in companies with steady and reliable cash flow, underperformed the market for a decade". Clearly, part of the story may be explained by the presence of a bubble in the stock market, but even after it burst in 2000, valuations remain at a much higher level after the crisis.

Possible explanations for the NPV approach failure are that it does not take into account important determinants of value such as intellectual capital, market power, and real options, hence, resulting in undervalued projects or corporations. A study by Ernst and Young mentioned previously estimates that only $25 \%$ of current market capitalization is based on cash flows anticipated in the next five years in a sample that includes both growth and value stocks. The other $75 \%$ of value may be explained by the aforementioned factors. Intellectual capital and market power are more relevant for growth stocks whereas real options are relevant for both, value and growth stocks.
Literature on real options has grown rapidly in the recent years. Much of it focuses on capital budgeting, but it can also be applied to corporate valuation. A real option is "the right but not the obligation to take an action (e.g. deferring, expanding, contracting, or abandoning) at a predetermined cost called the exercise price, for a predetermined period of time -the life of the option" (Copeland and Antikarov, 2001, p.5). This concept of real options has been developed as an analogy to financial options, where the underlying asset is a real investment opportunity.

The theory of option pricing is based on no-arbitrage equilibrium, where it is possible to replicate the option payoffs by building portfolios of traded securities, hence, to avoid arbitrage, the value of the option should be the same as the value of the replicating portfolio. The main caveat about the use of no-arbitrage equilibrium for real options valuation is that investment opportunities or projects are not traded. This difficulty may be overcome in the same way as it was done in the DCF approach, that is, by identifying a twin security for the project, which is traded in financial markets and has the same risk characteristics. Then, this twin security's required rate of return -computed based on CAPM- can be used as the appropriate discount rate. However, even if this twin security exists - which may not be the case always-, the fact that the project is a non traded asset demands an adjustment for the drift rate by a risk premium $\Psi$. Hence, risk-neutral valuation can be used replacing the drift rate $\alpha$ for an adjusted drift rate $\alpha^{*}$ as follows:

$$
\alpha^{*}=\alpha-\Psi
$$

This risk-neutral valuation may be used for a rich variety of real options. One of the 
most frequently encountered in projects is the real option to defer (D) the decision of making additional investments until i.e. there is more information about product demand. This option can be assimilated to a Call option where its value is the present value of the expected payoff from the option. This payoff is the maximum of the underlying asset's value -at the expiration of the option- minus the exercise price or zero:

$$
D=P V\left[E_{0}^{*}\left(\operatorname{Max}\left(S_{T}-X, 0\right)\right)\right]
$$

where:

- $\quad E^{*}$ denotes "risk-neutral" or equivalent Martingale expectations.

- $\quad$ ST is the value of the underlying asset at the time of expiration of the option. For real options the underlying is the real investment opportunity.

- $X$ is the exercise price which is the investment required to exercise the option.

- $T$ is the time to expiration of the option.

Finally, the volatility of underlying asset's value is measured by its standard deviation $\sigma$.

Table 1.1 shows how the value of option $\mathrm{D}$ changes when each of these variables increases:

Table 1.1

Option to Defer. Value Factors

\begin{tabular}{|c|c|}
\hline $\begin{array}{c}\text { FACTOR } \\
\text { (Increases) }\end{array}$ & $\begin{array}{c}\text { OPTION TO } \\
\text { DEFER } \\
\text { (Value) }\end{array}$ \\
\hline$S$ & Increases \\
\hline$X$ & Decreases \\
\hline$T$ & Increases \\
\hline$r$ & Increases \\
\hline$\sigma$ & Increases \\
\hline
\end{tabular}

Some other real options i.e. the option to abandon (A) a project, may be assimilated to a Put option instead. The value of such option is also the present value of its expected payoff but the payoff is computed the maximum of the exercise price -at the expiration of the optionminus the value of the underlying asset or zero:

$$
A=P V\left[E_{0}^{*}\left(\operatorname{Max}\left(X-S_{T}, 0\right)\right)\right]
$$

If the decision to defer may be done at different points in time before the option's expiration, $\mathrm{D}$ can be considered as an American option. The same can be said for the abandonment option if management may make such decision at different times before expiration. By exercising this option, management can abandon a project after being initiated, recovering only its scrap value. The costs saved are the exercise price in this case whereas the difference between the initial value of the project and the scrap value is the underlying asset's value.

Additional to the option to defer or to abandon, other real options frequently mentioned in the literature are:

- The Shutdown Option: it is the management's option to shutdown a plant when output price falls below variable cost. McDonald and Siegel (1985) model this option in a way that the decision to shutdown may be made costless. The option payoff at each period will be the maximum of revenue minus costs or zero since the firm may choose between producing and shutting down. The final value of the firm is the present value of the expected option payoff.

- The Option to Expand: similar to a call option where by making an additional investment I' -the exercise price for this option-, management can expand the scale of a project by a certain amount proportional to $S: S^{\prime}$. The payoff from this option will be and the value of the option will be the present value of its expected payoff. 
- The Option to Contract: is the opposite of the option to expand. Management may decide to contract the scale of the project by a certain percentage to $\left(1-S^{\prime \prime}\right)$, therefore, saving certain planned expenditures I", i.e. reducing advertising or the size of the plant if the demand of the product is not as strong as initially predicted. This type of real option is similar to a put option where the option payoff is $\left[\operatorname{Max}\left(S^{\prime \prime}-S^{\prime \prime}, 0\right)\right]$ and the option value is the present value of its expected payoff.

- The Option to Switch: it gives management the flexibility to switch i.e. technologies or outputs. It can be seen as a put option on the value of the investment opportunity under its current use and exercise price equal to its value under its alternative use.

- Growth Option: it emerges when the project is designed in phases i.e. discovery, product trials, production. In this case, additional investments will be made only if the discovery phase is successful. It is similar to a call option and the timing of those additional investments is uncertain and conditional on the discovery. The value of a growth option $(G)$ will be:

$$
\mathrm{G}=\mathrm{PV}\left[\mathrm{E}_{0}^{*}\left(\operatorname{Max}\left(\mathrm{S}_{\mathrm{t}}-\mathrm{X}, 0\right)\right)\right] .
$$

Recently, an approach to valuation based on real options has been suggested. This Real Options Approach (ROA) estimates the value of a project as the sum of its static or passive NPV and the value of the real options the project offers to management. Under ROA, a project or investment opportunity should be undertaken only if

$$
\begin{aligned}
& \text { ROA Value }= \\
& \text { Passive NPV + Real Option Value }>0
\end{aligned}
$$

Hence, according to ROA, just using passive NPV frequently undervalues projects. Another consequence of using $\mathrm{ROA}$ is that sometimes projects with negative NPV may be undertaken when the value of the real options it offers exceeds the negative NPV.

ROA corrects the NPV approach estimate in two ways. Firstly, by taking into account real options, it adds value to the project by introducing asymmetry on its cash flows. This implies that project cash flows cannot be calculated in a single "mean" scenario, even if the underlying probability distributions are symmetric (Kulatilaka and Marcus, 1992) Also, while the NPV approach fails to recognize the "strategic value" of a project resulting from its interdependencies with future, follow-up investments, and from competitive interaction, $\mathrm{ROA}$ does take these interdependencies into account, usually resulting in higher estimates than those based on the NPV approach (Trigeorgis, 1988).

Under ROA, higher uncertainty and more time before undertaking the project may increase the value of the project, contrary to what happens in the passive NPV approach. As it was shown above in Table 1, the value of the real option is greater since managerial flexibility becomes more valuable in these cases. The final project's value will be higher when the real options value increases by more than what the NPV decreases due to greater uncertainty or time to undertake the project.

As DTA, ROA recognizes the flexibility management has to avoid negative states of nature by deferring decisions until more information is gathered about the project's future cash flows. However, finding the right discount rate for the expected cash flows is difficult under DTA as well as under DCF as it was discussed above. Precisely, an advantage of $\mathrm{ROA}$ over these methods is that it uses financial option pricing theory to value real options. This theory have proved to be helpful in valuing real options, although it should be applied with some caution since there are some differences between financial and real options. 
An example of these differences is the stochastic nature of the exercise price for real options since the value of the necessary investment to exercise the option may change as time passes. Another difference is that the underlying asset's value may jump and its volatility may not be constant until expiration. These characteristics make a numerical method, i.e. Monte Carlo, more suitable to value real options than the standard analytical methods as the Black-Scholes or the Binomial model which are used frequently for financial option pricing.

On the other hand, although there is an extensive theoretical literature on ROA, the number of empirical studies on how this approach performs is much more limited. Paddock, Siegel, and Smith (1988) perform a study on bids to develop oil leases using a government discounted cash flows model and a deferral option. With any of these models they are able to explain only half of the actual winning bids. Adding the deferral option could not explain the high prices that were paid which the authors explain as a "winner's curse" problem. Bailey (1991) uses ROA with a shutdown option to explain the prices of seven palm and rubber plantations. He finds that in six out of seven cases, ROA explains better the actual stock prices compared to a DCF model, and the difference between these two models is statistically significant in two of those cases.

Quigg (1993) analyzes 2,700 land transactions in Seattle based on ROA incorporating an option to wait to develop the land. She runs regressions of property prices on building and lot sizes, building height and age, and dummy variables for location and season. She also calculates the price assuming the option would be exercised by building when the ratio of the building's price to the development cost was greater than one plus the market rate. After that, actual transaction prices are regressed against the option value and the regression value and finds that the option model fit is higher than in the regression model in nine out of fifteen cases. Additionally, when the option premium is added to the multiple regression, it is significant in fourteen out of fifteen cases.

More empirical evidence to support ROA is shown in Bulan (2001) who examines the implications of real option models with irreversible investment for the relationship between firm investment and uncertainty. Using data on 2,467 U.S. firms, she finds support for the predictions of $\mathrm{ROA}$ in the sense that firms delay investment during times of greater uncertainty. On the other hand, Moel and Tufano (2000) perform a study on 285 developed North American gold mines based on $\mathrm{ROA}$ including a switching option -between operating and shutting modes-. Their results are consistent with a real options model where mine closings depend on the price of gold, its volatility, operating costs and closing costs.

Tong and Reuer (2004) search for evidence on whether firms actually capture option value from their investments. They estimate the proportion of firm's value accounted for by growth options and link the growth option value to corporate investments that have been commonly viewed as providing valuable growth options. The empirical analysis examines internal and external corporate development activities of a panel of 293 manufacturing firms during 1989-2000. The results indicate that investments in research and development and in joint ventures contribute to growth option value, and that investments in tangible capital and in acquisitions have no effect in general.

Finally, Clark, Gaddad, Rousseau (2004) look at divestitures by 144 UK firms listed on the LSE from 1985 to 1991 and investigate whether and how accurately investors price the firm's option to abandon assets in exchange for their exit value. Theory prices this real option as an American style put. The empirical implications 
are that investors do price the abandonment option but that they price it imperfectly because the exit price is private information.

Not surprisingly, this empirical evidence shows that ROA explains actual prices better than DCF approaches. However, in most cases it does not explain fully the difference between actual prices and the passive NPV and I suggest two possible explanations for it. It could be the case of a failure in defining properly the stochastic process of the underlying asset which is crucial in applying option pricing, i.e. assuming a diffusion process when the actual one is a jump-diffusion process (Maya, 2003). Another possible explanation is that, sometimes, some other factors need to be considered to determine the value of the firm, i.e. intellectual capital and market power. In Maya (2004) I propose a Creative Destruction - Real Options Approach which incorporates all these three determinants of value: real options, intellectual capital, and market power, to explain actual stock prices of start-up firms in growth industries.

Nowadays there is no question that from a theoretical point of view, $\mathrm{ROA}$ is a much more appealing concept than passive NPV. However, its acceptance by practitioners has been very slow, mainly due to the difficulties in understanding and applying option pricing theory. Although extending option theory to real investments was first proposed more than twenty years ago, it was only in the last three to five years that such concept has really attracted the interest of large companies and consultants.

In a survey of thirty-four companies in seven industries, Triantis and Borison (2001) found that firms which have shown interest in $\mathrm{ROA}$ are those that operate in industries where large investments with uncertain returns are commonplace, i.e. oil, gas, and life sciences. In many cases, these are industries which have undergone major restructuring that makes traditional approaches to valuation less helpful, i.e. electric power. Finally, they tend to be engineering-driven industries where sophisticated analytical tools have been widely used. Surprisingly, the financial industry has shown less interest.

According to Miller and Park (2002), to date, mostly natural resources, utility, and $R \& D$ managers are using $R O A$ due to the accessibility to publicly traded prices to proxy option parameters. They cite Busby and Pitts (1997) study where questionnaires were sent to Finance Directors in all firms in the FT-SE 100 Index. This study found that $50 \%$ of them recognized options within their business, with most options being growth or abandonment. $35 \%$ of the respondents considered options as highly or extremely important in influencing investments decisions, however, more than 75\% did not have procedures for valuing real options, confirming that the main obstacle to its use in real world has been the complexity of real options pricing in spite of its widely recognized theoretical appealing.

\section{Conclusions}

It took more than twenty years for the DCF approaches, mainly the NPV, to replace Years to Payback and other ancient methods for capital budgeting and corporate valuation purposes. Yet this long wait proved to be worthy since after positioning itself as the most widely used approach to valuation, its reign seemed endless. Still in the nineties it continued to be the main approach, albeit an abysm between market prices and DCF values, a fact that neither academics nor practitioners could continue ignoring.

This NPV approach is based on the free cash flows the project or entity will generate in the future which are defined as the net cash flows to shareholders after future investments. It improves over those methods based on balance sheet's information in the sense that it measures 
the ability to generate cash and, as such, it gives a better estimate of the shareholder's wealth created by the project or entity. Additionally, it accounts for both the time value of money and the risk aversion, all combined through the riskadjusted discount rate.

Adding sensitivity analysis and simulating cash flows to compute NPV certainly improves the passive NPV approach to valuation. However, all these NPV approaches present a serious flaw which is that it assumes, from the beginning of the project, a commitment to certain investments which will be made at fixed points in time. In the real world, management may wait until more information is gathered i.e. about the product or the market, before committing more money to the project. As time passes and more information is available, uncertainty decreases and management may make a better decision.

A much more appealing approach -from a theoretical point of view- has taken a foothold into the valuation world. Building on the DCF

Empirical evidence shows that ROA explains actual prices better than DCF approaches. However, in most cases it does not explain fully the difference between actual prices and the passive NPV and I suggest two possible explanations for it. It could be the case of a failure in defining properly the stochastic process of the underlying asset which is crucial in applying option pricing, i.e. assuming a diffusion process when the actual one is a jumpdiffusion process. Another possible explanation is that, sometimes, some other factors need to be considered to determine the value of the firm, i.e. intellectual capital and market power. approach yet going further in the sense of incorporating flexibility in management investment decisions, and taking advantage of the advances in option pricing theory, the real options approach ( $\mathrm{ROA}$ ) has become the alternative approach to capital budgeting and, lately, to corporate valuation.

ROA corrects the passive NPV approach estimates in two ways. Firstly, by taking into market power.

Empirical evidence shows that ROA explains actual prices better than DCF approaches. However, in most cases it does not explain fully the difference between actual prices and the passive NPV and I suggest two possible explanations for it. It could be the case of a failure in defining properly the stochastic process of the underlying asset which is crucial in applying option pricing, i.e. assuming a diffusion process when the actual one is a jumpdiffusion process. Another possible explanation is that, sometimes, some other factors need to be considered to determine the value of the firm, i.e. intellectual capital and

Nowadays there is no question that from a theoretical point of view, ROA is a more appealing concept than passive NPV. However, its acceptance by practitioners has been very slow, mainly due to the difficulties in understanding and applying option pricing theory. 
Amran, M. and N. Kulatilaka. (1998). Real Options: Managing Strategic Investment in An Uncertain World. University Press. Oxford University.

Bailey, W. (1991). "Valuing Agricultural Firms: An Examination of the Contingent Claims Approach to Pricing Real Assets". En: Journal of Economic Dynamics and Control 15, pp.771791.

Black, F. and M. Scholes. (1973). "The pricing of options and corporate liabilities". En: Journal of political economy. 81. pp.637-659.

Bodie, Z., A. Kane, a nd A. Marcus. (2002). Investments. $5^{\text {th }} \mathrm{Ed}$. Boston.

McGraw-Hill Irwin

Boer, F.P. (2002). "Financial Management of R\&D 2002". http://www.boer.org/files/2002. pdf.

Brealey, R. A. and S. C. Myers. (2000). Principles of Corporate Finance. $6^{\text {th }} \mathrm{Ed}$. Boston. Irwin McGraw-Hill.

Bulan, L. (2001). "Real Options, Irreversible Investment and Firm Uncertainty: New Evidence from U.S. Firms". En: Working Paper, March, 2001.

Busby, J. and C. Pitts. (1997). "Real Options in Practice: An Exploratory Survey of How Decision Makers in Industry Think About Flexibility". En: Management Accounting Research 8. pp.169-186.

Clark, E., Gadad, M. and P. Rousseau. (2004). "Investor Valuation of the Abandonment Option: Empirical Evidence from UK Divestitures".http://www.realoptions.org/ papers2004/ClarkRealOp2004.pdf (July 31st, 2004).

Copeland, T., T. Koller, and J. Murrin. (2000). Valuation: Measuring and Managing the Value of Companies. $3^{\text {rd }}$ Ed. New York. John Wiley $\&$ Sons.
Copeland, T. and V. Antikarov. (2001). Real Options: A Practicioner's Guide. New York: Texere.

Cox, J.C., S.A. Ross, and M. Rubinstein. (1979). "Option Pricing: A Simplified Approach". En: Journal of Financial Economics 7. pp.229-263.

Dixit, A.K. and R.S. Pindyck. (1994). Investment Under Uncertainty. New Jersey. Princeton University Press.

Kulatilaka, N. and A. Marcus. (1992). "Project Valuation Under Uncertainty: When does DCF fail?". En: Journal of Applied Corporate Finance 5, 3. pp.92-100.

Kulatilaka, N. and L. Trigeorgis. (1994). "The General Flexibility to Switch: Real Options Revisited". En: The International Journal of Finance 6, 2. pp.778-798.

Maya, C. (2003). "Valuation of financial Assets using Monte Carlo: When the World is not so Normal". En: Revista de Economía del Rosario, 7, 1. pp.1-17

Maya, C. (2004). Valuating a Start-Up Firm: Creative Destruction and Real Options. http://www.realoptions.org/papers2004/ MayaCreativeDest.pdf (July 31, 2004).

McDonald, R., and D. Siegel. (1985). "Investment and the Valuation of Firms when There is an Option to Shut Down". En: International Economic Review 26, pp.331-349.

Merton, R.C. (1973). "Theory of Rational Option Pricing". En: Bell Journal of Economics and Management Science, 4, (Spring), pp.141-83.

Miller, L. and C. Park (2002). "Decision Making under Uncertainty: Real Options to the Rescue?". En: The Engineering Economist 47, 2. pp.105-151.

Moel, A., and P. Tufano. (2002). "When are Real Optins Exercised? An Empirical Study of Mine Closings". En: Review of Financial Studies 15. pp.35-64. 
Myers, S.C. (1976). "Postcript: Using Simulation for Risk Analysis" In S.C. Myers (ed.), Modern Developments in Financial Management. New York. Praeger Publishers.

Paddock, J.D., D. Siegel, and J. Smith. (1988). "Option Valuation of Claims on Physical Assets: The Case of Offshore Petroleum Leases". En: Quarterly Journal of Economics 103, 3. pp.479-508.

Quigg, L. (1993). "Empirical Testing of Real Option Pricing Models". En: Journal of Finance 48, 2. pp.621-640

Tong, T. and J. Reuer. (2004). Corporate Investment Decisions and the Value of Growth Options. http://www.realoptions.org/ papers2004/TongReuerGrowthOpt.pdf (July 31, 2004)

Triantis, A. and A. Borison. (2001). "Real Options: State of the Practice". En: Journal of Applied Corporate Finance 14, 2.pp. 8-24.
Trigeorgis, L.. (1986). Valuing Real Investments Opportunities: An Options Approach to Strategic Capital Budgeting. Unpublished, $\mathrm{Ph} . \mathrm{D}$. Dissertation. Harvard University.

Trigeorgis, L. (1988). "A Conceptual Options Framework for Capital Budgeting". En: Advances in Futures and Options Research 3. pp.145-167.

Trigeorgis, L. (1996). Real Options: Managerial Flexibility and Strategy in Resource Allocation. Cambridge. MIT Press.

Wilmott, P. (1998) Derivatives. John Wiley \& Sons, University edition.

Yao, H. and F. Pretorius (2004) "Empirical Testing of Real Options in the Hong Kong Residential Estate Market".

http://www.realoptions.org/papers2004/ YaoPretoriusHuimin.pdf (July 31st, 2004). 